\title{
JUURNAL_RU
}

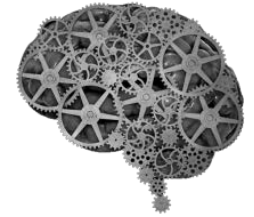

COMPANY GROUP "INTELLEKT"

\author{
Смоляков О.А. \\ Государственньй университет управления \\ Москва, Россия
}

doi: 10.18411/lj2016-3-76

\section{Учетное обеспечение управления доходами и расходами предприятия авиационной промышленности и методика их контроля}

Авиационное предприятие в настоящее время - это сложный организм, требующее пристального внимания всех сотрудников управленческого аппарата $[1 ; 7 ; 15]$. Особую роль в этом процессе играет организация контроля и учета расходов денежных средств и прибыли $[2 ; 11 ; 14 ; 17 ; 23 ; 30]$.

Актуальность выбранной для исследования темы определяется важностью оптимизации расходов и получения максимальной прибыли, не учитывая издержки промежуточных инстанций, непосредственно участвующих в выполнении поставленных задач авиационному предприятию.

Поэтому возникает острая необходимость с точностью определять размеры расходов на выполнение работ и получение доходов, нуждающихся в их доказательстве $[1 ; 3 ; 4 ; 13 ; 16 ; 22 ;]$. Не будем забывать о том, что авиационная промышленность нуждается в детальной точности и не терпит недочетов халатности и неверных решений $[8 ; 10 ; 24 ; 25]$.

Государство, являясь заказчиком для авиационных предприятий, стремится к оптимальному расходованию бюджетных средств и требует четкого выполнения поставленной им задачи, а также осуществляет жесткий и пристальный контроль $[3 ; 5 ; 6 ; 9 ; 12 ; 26 ; 27 ;]$. 
Мною были проведен обзор работы несколько предприятий для определения основных компонентов учетно-контрольного обеспечения. Выполнение работ, предложенных заказчиком имеет определенную структуру.

В качестве примера возьмем работы связанные с сервисным обслуживанием: выполнение периодических работ, мелкий ремонт финального продукта, ремонт отдельных элементов финального продукта, поставка запасных частей и т.д.

Работы начинается с открытия заказов на выполнение работ по сервисному обслуживанию образцов финального продукта, и производится предприятием в течении нескольких дней с момента получения от заказчика заявки или официального гарантийного письма.

На каждую конкретную работу, выполняемую в местах их проведения, где непосредственно находится объект, согласно предъявленному предложению (ведомости выполняемых работ) коммерческого (экспортного) контракта, открывается отдельный заказ с указанием его плановой себестоимости. На этапе планирования данной работы необходимо четко понимать и детально определять что нужно внести в эту себестоимость, спланировать и просчитать все этапы выполнения работ, затраты на промежуточные инстанции [18; 9; 20; $21 ; 28 ; 29]$. При организации работ необходимо учитывать, что заказ является основанием для проведения работ по сервисному обслуживанию образцов финального продукта соответствующими подразделениями предприятия. Bсе заказы утверждаются руководителем предприятия, далее отрабатывается извещение об открытии заказа которые направляются в подразделения исполнители работ сервисного обслуживания.

В процессе выполнения работ возникают случаи изменения условий выполнения заказа. В этом случае необходимо в срочном порядке сообщать об этих изменениях в подразделения которые являются исполнителями работ сервисного обслуживания. После получения от заказчика задания ему присваивается шифр задания. Для каждого задания этот шифр индивидуален и 
построен таким образом что бы быстро и точно определять конкретно выполняемую работу, показывать все расходы, а в последующем, полученные доходы на данную задачу [1].

Далее ответственное подразделение предприятия составляет проект перечня открытых заказов согласно предлагаемым работам, определяет непосредственных исполнителей и указывает сроки их выполнения. После получения данной информации оформляются бланки, учетные карточки конкретных заказов на выполнение работ с указанием, в том числе, заказчика, источников финансирования, сроков исполнения и цены работ, номера заказа и подразделения - исполнителя работ сервисного обслуживания. В итоге создается определенного вида картотека с точной информацией по выполняемой работе $[4,5]$.

Далее, проект перечня открытых заказов по контракту и оформленные надлежащим образом бланки заказов, являющиеся основой для его составления, утверждаются руководителем предприятия. Копии указанного перечня направляются заинтересованным лицам: руководителям подразделений сервисного обслуживания, руководителям сервисных бригад и другим должностным лицам предприятия (по мере необходимости) для исполнения и контроля, и в обязательном порядке, главному бухгалтеру. В начале каждого календарного года внутри предприятия обновляется (уточняется) перечень открытых заказов по всем заказам и осуществляется рассылка вышеперечисленным должностным лицам.

Для упорядочивания организации данной работы предприятию необходимо вести учет открытых заказов в специальной документации, которая находится у ответственного лица. Внесение изменения допускается только им.

При выполнении работ по заказам во всех первичных документах на расход заработной платы, материальных ценностей и денежных средств, а также плановых и отчетных документах должностными лицами предприятия, указывается номер (шифр) заказа. Что определяет точность в планировании и в 
последующем распределении денежных средств. Организация правильного распределения затрат по заказам (указание номера (шифра) заказа в соответствующих документах) обеспечивают и, как правило, контролируют на предприятии занимающихся сервисным обслуживанием:

руководитель сервисной бригады - исполнитель $\quad$ работ - в $\quad$ части оформления первичных расходных и отчетных документов об израсходовании материальных ценностей и денежных средств (распределение материальных затрат согласно всем накладным, перечню израсходованных материалов, табелей учета рабочего времени производственного персонала, авансовых отчетов о расходах на командировки и т.п.), разделительных ведомостей в строгом соответствии с перечнем действующих заказов;

руководитель, который занимается организацией работ по сервисному обслуживанию финального продукта - в части распределения заработной платы основного производственного персонала согласно ведомости учета отработанного времени по заказам, распределения руководителями сервисных бригад командировочных расходов, членов бригад согласно авансовым отчетам, и прилагаемым к ним, отчетным документам;

руководитель, который занимается логистикой - в части распределения транспортных расходов (при их наличии) согласно актам оказания транспортных услуг сторонними организациями, товарно-транспортным накладным и др.;

другие должностные лица, причастные к организации и выполнению работ по сервисному обслуживанию образцов финальной продукции - в части оформления служебных записок, заявок и счетов на закупку материальных средств, платежных документов на авансирование соисполнителей работ, приказов и распоряжений руководителя предприятия о направлении сервисных бригад в командировки и др.

Первичные расходные и отчетные документы, в обязательном порядке, передаются в бухгалтерию предприятия и являются основой для формирования 
должностными лицами бухгалтерии фактической стоимости работ по каждому заказу. Те документы, на которых отсутствует шифр заказа, указанный выше, бухгалтерией к исполнению и учету не принимаются. В стоимость работ, выполняемых в рамках конкретного заказа, включаются только затраты непосредственно связанные выполнением работы соответствующего шифру.

Предприятие строго отслеживает распределение и списание произведенных затрат по заказам и не допускает учета по другим производимым работам. После того как работы выполнены (фактически выполнены все работы, входящие в заказ) или, по каким то причинам выполнение работ было прекращено, предприятие закрывает заказы, как правило, в следующем порядке $[4,5]:$

руководитель сервисной бригады-исполнитель работ по факту их выполнения, независимо за счет какого источника они проводились, через руководителя управления организации выполняемых работ направляет заинтересованному подразделению предприятия уведомление о выполнении работ по заказу. При этом прилагаются отчетные документы. Если по каким то причинам выполнение работ по заказу было прекращено, то прилагается объяснительная записка (по факту частичного выполнения или досрочного их прекращения) с указанием причин приведших к этому.

Предприятие в обязательном порядке организует и ведет учет выполненных работ по заявкам, контролирует поступление уведомлений о выполнении (прекращении) работ по заказу и, ежемесячно, на их основе готовит уведомление о их закрытии, в проект которого включаются все выполненные (прекращенные) в этот период заказы.

После того как были списаны дополнительные затраты по выполненным работам осуществляется закрытие заказа и дальнейшее распределение затрат запрещается.

Ответственным за организацию и ведение учета и списание фактических затрат является главный бухгалтер. 
Учет и списание фактических затрат должно обеспечить предприятию авиационной отрасли, занимающегося сервисным обслуживанием:

своевременное полное и достоверное отражение в бухгалтерских документах и отчетных формах фактических затрат, отнесенных на выполнение конкретных работ по сервисному обслуживанию образцов финальной продукции (заказов), а также непроизводительных расходов и потерь при их проведении;

сопоставимость плановых и фактических данных по затратам (начиная с момента открытия заказа и до момента его закрытия), выявление возможностей снижения фактической стоимости проводимых работ и увеличение доли прибыли, планируемой предприятием к получению от их выполнения;

соблюдение установленного порядка группировки и распределения затрат по видам работ, источникам финансирования, конкретным заказам, календарным периодам, статьям затрат (прямые и косвенные) и калькуляционным статьям расходов;

своевременное списание затрат по выполненным (прекращенным) заказам (работам).

Учет фактических затрат по выполняемым работам по сервисному обслуживанию образцов финальной продукции на авиационных предприятиях, как правило, организуется позаказным методом, позволяющим обеспечить исчисление фактической стоимости каждой выполненной работы.

Обеспечение сопоставимости плановых и учетных данных при планировании, учете и калькулировании себестоимости выполняемых работ с данными бухгалтерского учета их фактических затрат, достигается путем установления единых методов определения состава затрат и их классификации. К которым относятся:

прямые затраты - расходы, связанные с выполнением конкретных заказов (работ сервисного обслуживания), которые могут быть отнесены непосредственно на заказ на основании первичной документации по прямому 
признаку (материальные средства, непосредственно израсходованные на работы по сервисному обслуживанию, выплаченная заработная плата и командировочные расходы членов сервисных бригад, расходы по транспортировке и т.п.). Первичная документация составляется с обязательным указанием номеров (шифра) заказов, по которым осуществляется распределение затрат;

косвенные затраты-расходы, связанные с выполнением всех работ (заказов), выполняемых предприятием (расходы на организацию, управление и содержание предприятия). Например, заработная плата, выплаченная административно - управленческому персоналу. Распределение косвенных затрат, так называемых «накладных расходов», по конкретным заказам производится пропорционально основной заработной плате, выплаченной членам сервисных бригад (основного производственного персонала, непосредственно занятого выполнением работ сервисного обслуживания (заказов);

источники финансирования (государственный бюджет, собственные средства заказчика и тд.)

календарные периоды-текущие, относящиеся к объему выполняемых работ в отчетном периоде и единовременные, относящиеся к объему работ, выполняемых в течении времени, превышающего отчетный период. Затраты распределяются по календарным периодам таким образом, чтобы сумма затрат отчетного периода отражала все затраты, относящиеся к объему выполненных в этом периоде работ по конкретному заказу;

калькуляционные статьи расходов.

Также предприятие выполняет аналитический учет фактических затрат выполняемых работ по заказам. Ведется данная работа в бухгалтерии с использованием карточек учета, указанных выше.

После того, как работа полностью выполнена или, по каким то причинам, работа прекращена, на предприятии проводится инвентаризация. В процессе 
инвентаризации устанавливается фактическое наличие оставшихся материальных ценностей, определяется их техническое состояние, обеспечивается сдача материальных ценностей на склад, а также списание их стоимости в уменьшение затрат по выполненным (прекращенным) работам.

Основная задача инвентаризации - рассмотрение и проверка состава отнесенных на тему фактических затрат и обоснованность их списания.

На основании вышеперечисленного формируются цены выполненных работ. Исходной базой цен являются обоснованные затраты предприятия по выполненным работам (фактическая себестоимость работ) и прибыль. Для формирования проектов цен по заказам представляются, как правило, нижеперечисленные расчетно -калькуляционные материалы с приложением копий первичных оправдательных документов, подтверждающих эти затраты (при их наличии):

главным бухгалтером - карточки учета фактических затрат;

руководителем подразделения непосредственно выполняющего сервисное обслуживание - исполнителя работ-расшифровки материальных затрат и расшифровки трудозатрат;

ответственным за управление организации работ - расшифровки затрат командировочных расходов;

ответственным за логистику - расшифровка затрат за транспортные расходы.

Названные документы являются основой для формирования предприятием себестоимости работ, отчетных калькуляций и проектов протоколов фиксированных цен по выполненным работам.

В дальнейшем результат выполненных работ проходит поэтапную проверку представителями заказчика, а если заказчиком является государство, то в процесс контроля вступают государственные контролирующие органы.

Из всего вышесказанного вытекает вывод, что для получения точного и объективного результата, а также единого учетно-контрольного обеспечения 
необходима разработка модели учетно-контрольного обеспечения управления доходами и расходами предприятия, которая в дальнейшем, в свою очередь, облегчит процесс подтверждения перед заказчиком целенаправленного расходования денежных средств при выполнении работ.

\section{Литература:}

1. Антонов А.П., Артемьев В.В., Добромыслова О.В. «Самолеты возвращаются в строй». М.: ИД ВВФ, 2005 г.

2. Бодяко А.В. Концептуальная характеристика роли бухгалтерского учета и контроля в иерархии корпоративной системы управления Сибирская финансовая школа. - 2015. - № 3 (110). - С. - 68-74.

3. Бодяко А.В. Необходимость планирования работы аудитора в соответствии с международным стандартом аудита 300 «Планирование». Вестник ИЭАУ. -2014. - № 5. - С. 1-4.

4. Бодяко А.В. Разработка внутрифирменных документов по оплате труда и расчетам с работниками в соответствии с новыми требованиями законодательства Вестник Университета (Государственный университет управления). - 2014. - № 4. -С. 153-157.

5. Бодяко А.В. Разработка комплексного методического обеспечения процедур внутрикорпоративного контроля расчетов в сложных хозяйственных структурах холдингового типа В сборнике: Актуальные проблемы учета, экономического анализа и финансово-хозяйственного контроля деятельности организаций. Материалы II Международной заочной научно-практической конференции. Под редакцией Д. А. Ендовицкого, Н. Г. Сапожниковой; Воронежский государственный университет. - 2015. - С. 133-135.

6. Бодяко П.М., Рогуленко Т.М., Пономарёва С.В., Бодяко А.В. Совершенствование организации бухгалтерского учета и контроля 
обязательств непубличных производственных компаний по кредитам и займам / П.М. Бодяко, Т.М. Рогуленко, С.В. Пономарёва, А.В. Бодяко // М.:Издательство «Русайнс» 2015 - 256с.

7. Горизонты ПАО «ОАК», М.: ПАО «ОАОК, 2015, 2016.

8. Добрынин А.И., Экономическая теория. М.: ИНФРА-М, 2016.

9. Клиценко В.И., «От МиГ-1 до МиГ-35». М.: АВИАМИР, 2009.

10. Майкл Мексон, Майк Альберт, Франклин Хедоури Основы Менеджмента. М.: Издательство Дело, 2006.

11. Мироненко В.М Аудит выполнения товариществом собственников жилья целевой установки его создания. В сборнике: Современное состояние и перспективы развития бухгалтерского учета, экономического анализа и аудита. материалы Международной научно-практической конференции. под науч. редакцией Е.М. Сорокиной. Иркутск, - 2013. - С. 443-447.

12. Мироненко В.М. Аудит отчетности экономических субъектов топливноэнергетического комплекса Вестник Университета (Государственный университет управления). - 2015. - № 3. - С. 159-163.

13. Мироненко В.М. Проблемы разработки рабочих документов аудитора с учетом специфики аудируемых объектов. В сборнике: Современное состояние и перспективы развития бухгалтерского учета, экономического анализа и аудита. Материалы Всероссийской научно-практической конференции. под научной редакцией Е.М. Сорокиной. 2012. - С. -319322.

14. Мироненко В.М., Зеленов В.В. Учет операций с иностранной валютой на валютных счетах// Сибирская финансовая школа. 2015. № 3 (110). С. 7983.

15. Обзор СМИ ПАО «ОАК», М.: ПАО «ОАК», 2016.

16. Пономарева С.В. Базовые принципы теории информации, управления и бухгалтерского учета, их причинно-следственные связи Вестник Университета (Государственный университет управления). -2014. - № 3. C. 158-163. 
17. Пономарева С.В. Бизнес-информация и деловые знания в конвергенции учетной и управленческой парадигм // С.В. Пономарева, И.В. Лескова, В.В.Зеленов // Духовная ситуация времени. Россия XXI век. 2015. № 2 (5). C. 100-102.

18. Пономарева С.В. Информация как стратегический ресурс в системе управления бизнесом / Пономарева С.В., Лескова И.В., Зеленов В.В. // Российская наука и образование сегодня: проблемы и перспективы. 2015. № 3 (6). С. 101-104.

19. 19. Пономарева С.В. Концептуальные положения финансовой стратегии развития компаний сферы интеллектуальных бизнес-услуг // Вестник Университета (Государственный университет управления). - 2013. - № 15. - C. 059-068.

20. Пономарева С.В. Принципы, методы и инструменты формирования бухгалтерской отчетности для целей управления сегментами бизнеса // Вестник Университета (Государственный университет управления). 2013. № 4. С. 181-187.

21. Рогуленко Т.М. Бухгалтерский учет расчетов с контрагентами строительной организации / Т.М. Рогуленко // Бухучет в строительных организациях. 2012. № 9. С. 49-51.

22. Рогуленко Т.М. Международные стандарты аудита Учебник и практикум / Т.М. Рогуленко, С.В. Пономарева, А.В. Бодяко и др. / М.: Издательство Юрайт - 2015. Сер. 58 Бакалавр. Академический курс (1-е изд.)

23. Рогуленко Т.М. Методика и технология проведения подтверждающего аудита /Аудиторские ведомости. - 2013. -№ 1. - С. 15-32.

24. Рогуленко Т.М. Проблемы перехода российского бухгалтерского учета на международные стандарты финансовой отчетности /Вестник Университета (Государственный университет управления). - 2013. - № 4. - C. 187-191.

25. Рогуленко Т.М. Роль контроля в реализации функций управления рыночной экономикой / Вестник Университета (Государственный университет управления). 2013. № 15. С. 035-040. 
26. Рогуленко Т.М. Совершенствование методики формирования данных и анализа финансового состояния организаций в ходе налоговых проверок с учетом отраслевых особенностей / В.А. Сенков В.А., Т.М. Рогуленко Т// Вестник Университета (Государственный университет управления). 2015. № 5. С. 159-162.

27. Рогуленко Т.М. Теория системности экономического познания и ее влияние на организацию системы контроля управления хозяйствующим субъектом / Т.М. Рогуленко // Сибирская финансовая школа. 2015. № 2 (109). С. 106-110.

28. Рогуленко Т.М. Учет капитала организации / Т.М.Рогуленко // Бухучет в строительных организациях. 2012. № 5. С. 16-21.

29. Рогуленко Т.М. Учет материально производственных запасов / Т.М. Рогуленко // Бухучет в строительных организациях. 2012. № 7. С. 21-25.

30. Совершенствование организации бухгалтерского учета и контроля в автономных образовательных учреждениях / Горюнова Н.Д., Рогуленко Т.М., Пономарева С.В. // монография / Москва, 2014

31. Сокол С.И., Архипов А.А., Белошапкин В.В., Шиков Ю.В. «О тех кто возвращает самолеты в небо». Рязань: ПРИЗ, 2010. 